\title{
建筑工程安全生产管理问题研究
}

\author{
金超陈伟良
}

浙江中成建工集团有限公司，浙江 绍兴 312000

[摘要] 众所周知，建筑业一直都是高危行业，但其在我国国民经济发展中又是不可或缺的重要产业。企业可否在剧烈的市场 竞争中突起的关键恰是管理工作的好坏。安全是关系到民生的头等大事，是我们的生活，生产，支持。坚持“安全第一”的 理念, 是任何工作的前提和保证。因此, 基于国内外安全生产制度的比较, 并结合我国建筑安全生产管理的现状, 对安全事 故的发生的原因进行了分析，从而针对建设工程管理中的安全问题，总结了相应的防范对策。

[关键词]建筑业; 安全生产管理; 措施

DOI：10.33142/aem.v1i1.795 中图分类号: TU714 文献标识码：A

\section{Research on Safety Production Management of Construction Engineering}

\author{
JIN Chao, CHEN Weiliang
}

Zhejiang Zhongcheng Construction Engineering Group Co., Ltd., Shaoxing, Zhejiang, 312000

\begin{abstract}
As we all know, the construction industry has always been a high-risk industry, but it is an indispensable industry in the development of our national economy. The key to whether enterprises can stand up in the fierce market competition is management. Safety is the top priority for people's livelihood, which is the support of our life and production. The principle of adhering to the "Safety First" is the premise and guarantee of any work. Therefore, based on the comparison of domestic and foreign production safety systems and combining with the current situation of construction safety production management in our country, the cause of safety accident is analyzed. In view of the safety problems in the construction project management, this paper summarizes the corresponding preventive countermeasures.
\end{abstract}

Key words: construction industry; safety production management; measures

\section{引言}

在中国, 由于大规模地建造, 近四千万建筑工人组成了世界上最大的劳动力。全国施工安全生产事故时有发生, 2018 年建筑施工安全生产形势比去年同期事故起数增加 20 起、死亡人数增加 25 人, 同比分别上升 $5.49 \%$ 和 $5.52 \%$ 。这 些事故不仅导致相应的施工企业都面临着不同程度的经济损失, 也使建筑工人的安全受到威胁, 使施工安全管理形势 严峻, 对社会也产生了不良的影响。另外, 通过对前几年安全事故的总结和大量文献的研究显示, 这些事故的主要原 因是政府对建筑市场管理不完善, 相关监督人员对安全生产管理力度不足; 建筑施工安全生产制度和相关制度的不完 善; 施工工人文化素质不高且缺乏自我保护意识, 没有接受良好的安全教育; 建筑施工现场的安全技术措施有待提高, 不重视对重大危险源的安全施工方案等。

\section{1 我国建筑工程安全生产管理现状}

近几年该领域的安全状况仍然有待改进, 虽然 2017 年安全生产局势稍有好转, 事故起数和导致死亡人数都有所下 降。但在 2018 年, 形势又有所恶化, 安全事故与去年同期增加 773 起, 上升 $16.19 \%$ 。整体而言, 安全状况仍然没有 得到有效改善, 事故起数依然较多。由于经济技术的发展, 对建筑业的安全生产要求也越来越高, 而不能停留在过去 的评价标准。在这个信息化的时代, 到处都充满了机遇和挑战, 建筑业应当接受挑战抓住机遇实现新时代跨越式发展。

这些年来, 我国的建筑业飞速发展, 越来越多的建筑物拔地而起。而建筑施工企业在金钱和利益的趋势下, 盲目 施工, 只追求工程进度, 忽视安全生产管理, 导致安全事故日益增加, 几乎每天都有施工人员受到生命财产的威胁。 而人民的安全受到威胁, 就是国家的利益在遭受损害, 在如此形势之下, 我国建筑相关企业必须认清现实, 改变当前 现状，加强施工安全管理。只有这样，我国才能实现真正的国富民强。

\section{2 建筑工程安全生产管理存在的问题}

2015 年 3 月 24 日 19 时 30 分，云南省昭通市的新建清真寺发生垮塌事故，造成 3 名施工人员死亡、 1 人受伤。 4 月 1 日 19 时 27 分, 四川省内江市市中区一高速公路施工现场发生龙门吊垮塌事故, 造成 3 人死亡, 1 人受伤。 4 月 2 日 19 时, 陕西省咸阳市渭城区一工地施工过程中发生火灾, 造成 4 人死亡。这些都是我们最不想面对的数字, 却是我 国建筑业当前真实的现状。2001 建筑业完成了近 800000 套, 共 188000 万 $\mathrm{m}^{2}$ 的单位工程已完成建筑面积, 其中 500000 多个已建成, 面积达到了 98000 万 $\mathrm{m}^{2}$ 。与此同时, 中国的建筑业每年有超过一千人因事故死亡, 经济损失高达 100 亿 元。再此根据相关资料显示, 总结出阻挡施工安全管理水平程度的几个方面的问题: 


\section{1 法律法规方面}

主要体现在建筑工程相关律法不够完善, 安全生产责任制落实不到位。在我国 280 余项关于建筑工程的律法中, 以法的方式呈现、对安全生产管理非常关键的是《劳动法》。但跟别的国家相比, 我国依然存在着法律制度不健全, 建 筑相关政法的可操作性差, 甚至还存在着反复和穿插等问题。另外目前的施工企业中, 能够真正落实安全管理机构及 其制度的并不多, 项目关键岗位的管理人员没并有承担好应有的责任、项目层层分包、转包等问题毫无疑问会造成施 工现场管理混乱，隐患多多。

\section{2 政府监管方面}

政府监管存在的问题主要体现在建筑工程管理不完善, 安全监督管理力度不足。一些建筑企业为得到工程, 在投 标时忽略安全生产的经费, 最后导致施工现场安全隐患增加。此外, 监督部门在监督过程中缺乏对违规行为的处罚, 监督方式单一，没有与社会经济保持一致步伐。

\section{3 人员素质方面}

人员素质方面主要体现在施工工人素质低下, 对其的安全教育严重滞后。首先, 建筑业吸纳农村剩余劳动力 31370000 人, 为整个行业的工人占 $80.58 \%$ 。而这些农民工只接受过基本培训和教育, 有些工人甚至根本没有收到过安 全教育和班前活动, 更不用说是专门的技术学习和安全技能培训, 从而自我保护意识差。

\section{3 建筑工程安全生产管理的对策}

\section{1 明确监督部门的职责}

施工企业必须建立保障安全的经费, 采用专款专用, 加大法律法规的宣传力度。对于应当纳入监管范围的项目实 行有效监管, 保证其安全可行。另外, 监理人员应当明确其每个人的监督范围, 采用分区域划分工程进行监管, 将工 程责任划分到个人, 若监理人员没有承担好自己的责任, 部门其他人员都可以进行检举, 而施工单位必须针对监理人 员提出的问题，做好整改工作，并且每一个施工阶段都应上报，由监理人员检验合格才能完成下一个工程部分。

\section{2 完善安全生产责任制}

施工企业必须严格执行安全生产责任制度, 使工作实现真正的有法可依、有章可循, 严格遵守国家颁布的相关法 律法规。同时, 在开展具体的前施工企业和建设单位的工作, 首先要准备好相关的安全责任制, 企业必须加大安全教 育投入, 对施工作业人员进行严格的教育培训。施工企业的安全管理培训应方式多样, 合理, 形成一个系统, 达到严 格、严密、严谨, 务实的要求。只有将安全生产责任和安全教育深入每一个建筑工人, 才能创造一个良好的每个人心 中有安全的施工氛围。

\section{3 准确识别及控制危险源}

首先应配备足够数量的, 且通过安全技术管理部门培训审核的专职安全生产技术人员。只有这些具备工程专业知 识, 对现场各类情况都能掌握在手的技术员, 做好施工现场可能出现的安全问题进行预测, 特别是对安全技术措施四 项新技术, 自然灾害的防治, 防火防爆措施等极其容易出现安全隐患的方面, 做好事故出现的准备工作, 才能临危不 乱, 出现事故也不慌乱, 也就是说我们必须提高安全技术措施, 用科学的手段达到安全的目的。另外, 作业现场应当 能够准确地识别和控制危险源。这是一个项目前期管理任务, 只有在事前进行才能有效地避免事故发生。风险识别, 必须在每个员工的工作区域内有所通知，建立危险源的安全警示标志。

\section{4 总结}

对安全管理这门学科的不断研究, 其主要目的是通过加强对施工过程的管理, 以保护劳动者的健康和安全, 以及 工程的安全, 并且在保证工程质量的前提下对各种资源和生产工具最大限度的利用, 最终使经济健康有序地运行和发 展。安全管理作为一个工程安全的保障, 有它的特殊性, 首先安全管理是长期的和严肃的, 安全管理伴随一个工程从 最开始直至结束, 安全管理关系到整个工程的安全, 是一个十分严肃的课题, 并且一刻都不能松解, 其次安全管理是 动态的, 各个工程都有各自的特殊性, 而其出现的安全管理问题也是不尽相同, 十分考验管理者的能力。因此, 我们 更应该牢记 “以人为本” 的安全理念, 利用当代先进的科学技术, 加强对施工过程的控制。只有这样才能从根本上解 决我国工程建设中安全管理的种种弊端，不断降低安全事故发生概率。

\section{[参考文献]}

[1]谷佳骅.建筑工程安全生产管理问题研究 [J].上海安全生产, 2017 (4) : 54-57.

[2] 梁立峰。建筑工程安全生产管理及安全事故预防 [J].广东建材, 2011,27 (2) : 103-105.

[3]俞金浅析建筑工程安全生产管理的影响因素及改进对策 [J].科学技术创新,2014(19): 184-184.

[4]伋雨林. 完善建设工程安全生产管理体制 [J]. 建筑安全, 2004, 19 (2) : 18-20.

[5]高武. 对当前建筑工程安全生产管理工作的思考 [J]。企业技术开发：下, 2009,28(4) : 104-105.

[6] 郭红英, 康香萍. 建筑工程安全生产管理的特点和难点 [J]. 煤炭技术, 2011, 30 (6): 154-156.

[7] 康香萍.建筑工程安全生产管理现状调查与简析 [J]. 煤炭工程, 2011, 1(4) : 136-138.

作者简介: 金超（1990-)，本科，浙江中成建工集团有限公司助理工程师，从事建筑工程管理工作。 